\title{
An Unusual Case of Serotonin Syndrome with Oxycodone and Citalopram
}

\author{
Clare Walter, ${ }^{1}$ David Ball, ${ }^{2}$ Mary Duffy, ${ }^{3}$ and James D. Mellor ${ }^{1}$ \\ ${ }^{1}$ Pharmacy Department, Peter MacCallum Cancer Centre, St. Andrew's Place, East Melbourne, VIC 3002, Australia \\ ${ }^{2}$ Division of Radiation Oncology and Cancer Imaging, Peter MacCallum Cancer Centre, St. Andrew's Place, East Melbourne, \\ VIC 3002, Australia \\ ${ }^{3}$ Division of Cancer Nursing, Peter MacCallum Cancer Centre, St. Andrew's Place, East Melbourne, VIC 3002, Australia \\ Correspondence should be addressed to James D. Mellor, dan.mellor@petermac.org
}

Received 22 February 2012; Accepted 1 April 2012

Academic Editors: S. Aksoy and A. Goodman

Copyright ( $) 2012$ Clare Walter et al. This is an open access article distributed under the Creative Commons Attribution License, which permits unrestricted use, distribution, and reproduction in any medium, provided the original work is properly cited.

A 77-year-old female with recurrent non-small-cell lung cancer presented to a hospital outpatient clinic with tremor, weakness, inability to coordinate motor movements, and confusion. It was suspected that the symptoms were due to possible central nervous system metastases; however, a CT scan of her head was unremarkable. The lung clinic liaison pharmacist took a medication history from the patient, complimented by extra information from the patient's community pharmacy. The pharmacist suspected the rare side effect of serotonin syndrome was responsible for the patient's presenting symptoms caused by the combination of oxycodone and citalopram. The patient's symptoms resolved soon after oxycodone was changed to morphine.

\section{Introduction}

Oxycodone is an opioid analgesic widely used in the treatment of moderate to severe cancer-related pain. It is available in immediate- and sustained-release oral formulations. Depression is also a disabling comorbidity which is common in patients with malignancies, particularly those who have advanced or metastatic disease. It is estimated that up to $15-25 \%$ of cancer patients suffer from depression [1]. Citalopram is a selective serotonin reuptake inhibitor licensed to treat the symptoms of depression.

\section{Case Presentation}

A 77-year-old female with recurrent non-small-cell lung cancer presented to the outpatient lung clinic complaining of tremor, weakness, inability to coordinate motor movements, and confusion. Central nervous system metastases were suspected, and a CT scan of the head was ordered.

The patient's medications were reported as oxycodone (slow release) $50 \mathrm{mg}$ twice daily, oxycodone (immediate release) $5 \mathrm{mg}$ when required, esomeprazole $40 \mathrm{mg}$ twice daily, temazepam $10 \mathrm{mg}$ at night, and docusate $100 \mathrm{mg}$ with sennosides $16 \mathrm{mg}$ twice daily. There was confusion as to whether this list was complete.

A telephone conversation with the patient's community pharmacist revealed in addition to her reported medications that she had recently picked up a repeat prescription of citalopram $20 \mathrm{mg}$ once a day, after not having it dispensed for several months. Diazepam had also recently been prescribed by her general practitioner for restless legs. The oxycodone had been started several months earlier (rotated from morphine) for cancer-related pain during the period that the patient was not taking her citalopram.

Further discussion with the patient elucidated that the symptoms started shortly after recommencing the citalopram. The lung clinic pharmacist suspected a drug interaction between citalopram and oxycodone which had resulted in serotonin syndrome. Use of the Naranjo probability scale indicated a probable relationship between the combination of oxycodone and citalopram and the serotonin symptoms [2]. The symptoms satisfied the Sternbach diagnostic criteria for serotonin syndrome [3].

Oxycodone was changed back to morphine, and the esomeprazole was reduced to $40 \mathrm{mg}$ daily (which in turn should improve citalopram clearance). The symptoms 
resolved within 48 hours, and the CT scan later came back clear.

\section{Discussion}

Serotonin syndrome is a serious adverse reaction thought to result from hyperstimulation of brainstem 5-HT1A and 2A receptors [4]. Coadministration of oxycodone with serotonin reuptake inhibitors has only recently been associated with the development of serotonin syndrome. An extensive literature search revealed only four previous reports of serotonin syndrome involving oxycodone $[5,6]$. The opioids of the phenylpiperidine series: pethidine, tramadol, methadone, fentanyl, dextromethorphan, and propoxyphene are weak serotonin reuptake inhibitors and are thus known to have an association with serotonin symptoms [7]. Oxycodone is a morphine analogue and so does not fall into this category of opioids. An alternative explanation is required.

Oxycodone differs from most other opioids in having a significant affinity for kappa opioid receptors [8]. While most of the drug is N-demethylated by CYP 3A4 to noroxycodone, approximately 10\% is O-demethylated by CYP 2D6 to the very potent active metabolite, oxymorphone $[8,9]$. Compared to oxycodone, oxymorphone has a higher affinity for the mu opioid receptor and is 14 times as potent as oxycodone [10].

Other potential contributing factors for the drug interaction include the following:

(i) a pharmacokinetic interaction between citalopram and esomeprazole, reducing the citalopram clearance. However, the patient had been on this combination for sometime without experiencing serotonin effects [11-13];

(ii) the inhibition of CYP 2D6 by citalopram affecting the metabolism of oxycodone. However, this inhibition is only classified as "weak" [9]. Available data indicates that impaired activity of CYP 2D6 is associated with only small changes in oxycodone pharmacokinetics, which do not usually result in altered oxycodone pharmacodynamics [14]. Also, if there were any effect, it would result in less of the active oxymorphone metabolite, rather than more;

(iii) opioids do not directly stimulate serotonergic neuronal discharge but disinhibit neuronal activity by suppressing GABA-mediated inhibition [15]. Thus, the short-term effect of morphine and perhaps other opioids is to increase serotonin release in widespread areas of the forebrain [16]. However, the patient had been on the same dose of oxycodone for 3 months prior to the onset of symptoms;

(iv) the patient may have been an extensive CYP 2D6 metaboliser. Whilst the metabolism of oxycodone to oxymorphone via CYP 2D6 is not responsible for all of the effects of oxycodone, experimental results indicate it does make a significant contribution in extensive CYP 2D6 metabolisers [17].
TABLE 1

\begin{tabular}{|c|c|c|}
\hline Drug & Metabolised by CYP & Inhibits CYP \\
\hline Citalopram & $3 \mathrm{~A} 42 \mathrm{C} 19$ & $\begin{array}{l}\text { 1A2, 2D6, } 2 \mathrm{C} 19 \\
\text { (weak) }\end{array}$ \\
\hline Esomeprazole & $2 \mathrm{C} 19,3 \mathrm{~A} 4$ & $2 \mathrm{C} 19$ \\
\hline Oxycodone & $\begin{array}{l}\text { 3A4 (to form noroxycodone) } \\
\text { 2D6 (to form oxymorphone) }\end{array}$ & \\
\hline
\end{tabular}

Table 1 summarises the activity of the relevant isozymes of the hepatic cytochrome P450 system [9, 12-14].

\section{Conclusion}

Whilst serotonin syndrome is not listed as an adverse event within the product information for OxyContin tablets when given in combination with a selective serotonin reuptake inhibitor, the small number of existing case studies to date suggests that it is prudent to closely monitor patients receiving this combination. The mechanism of interaction is unclear and warrants further investigation.

\section{Conflict of Interests}

The authors have no conflict of interests, financial or otherwise, to declare in relation to this paper.

\section{References}

[1] National Cancer Institute, “Depression (PDQ)," 2012, http:// www.cancer.gov/cancertopics/pdq/supportivecare/depression/ Patient/page2.

[2] C. A. Naranjo, U. Busto, and E. M. Sellers, "A method for estimating the probability of adverse drug reactions," Clinical Pharmacology and Therapeutics, vol. 30, no. 2, pp. 239-245, 1981.

[3] H. Sternbach, “The serotonin syndrome," American Journal of Psychiatry, vol. 148, no. 6, pp. 705-713, 1991.

[4] A. Graudins, A. Stearman, and B. Chan, "Treatment of the serotonin syndrome with cyproheptadine," Journal of Emergency Medicine, vol. 16, no. 4, pp. 615-619, 1998.

[5] H. Karunatilake and N. A. Buckley, "Serotonin syndrome induced by fluvoxamine and oxycodone," Annals of Pharmacotherapy, vol. 40, no. 1, pp. 155-157, 2006.

[6] C. J. Rosebraugh, D. A. Flockhart, S. U. Yasuda, and R. L. Woosley, "Visual hallucination and tremor induced by sertraline and oxycodone in a bone marrow transplant patient," Journal of Clinical Pharmacology, vol. 41, no. 2, pp. 224-227, 2001.

[7] E. E. Codd, R. P. Shank, J. J. Schupsky, and R. B. Raffa, "Serotonin and norepinephrine uptake inhibiting activity of centrally acting analgesics: structural determinants and role in antinociception," Journal of Pharmacology and Experimental Therapeutics, vol. 274, no. 3, pp. 1263-1270, 1995.

[8] F. B. Ross and M. T. Smith, "The intrinsic antinociceptive effects of oxycodone appear to be $\kappa$-opioid receptor mediated," Pain, vol. 73, no. 2, pp. 151-157, 1997.

[9] OxyContin (Oxycodone) Australian approved product information. Mundipharma Pty Limited, Sydney, Australia. Date of TGA approval or last amendment, 2010. 
[10] M. P. Davis, J. Varga, D. Dickerson, D. Walsh, S. B. LeGrand, and R. Lagman, "Normal-release and controlled-release oxycodone: pharmacokinetics, pharmacodynamics, and controversy," Supportive Care in Cancer, vol. 11, no. 2, pp. 84-92, 2003.

[11] K. Baxter, Ed., Stockley's Drug Interactions, Pharmaceutical Press, London, UK, 9th edition, 2010.

[12] Nexium (Esomeprazole) Australian approved product information. AstraZeneca Pty Limited, Sydney, Australia. Date of TGA approval or last amendment, 2011.

[13] Cipramil (Citalopram) Australian approved product information. Lundbeck Australia Pty Limited, Sydney, Australia. Date of TGA approval or last amendment, 2011.

[14] O. Kummer, F. Hammann, C. Moser, O. Schaller, J. Drewe, and S. Krähenbühl, "Effect of the inhibition of CYP3A4 or CYP2D6 on the pharmacokinetics and pharmacodynamics of oxycodone," European Journal of Clinical Pharmacology, vol. 67, no. 1, pp. 63-71, 2011.

[15] T. Jolas and G. K. Aghajanian, "Opioids suppress spontaneous and NMDA-induced inhibitory postsynaptic currents in the dorsal raphe nucleus of the rat in vitro," Brain Research, vol. 755, no. 2, pp. 229-245, 1997.

[16] R. Tao and S. B. Auerbach, "Involvement of the dorsal raphe but not median raphe nucleus in morphine-induced increases in serotonin release in the rat forebrain," Neuroscience, vol. 68, no. 2, pp. 553-561, 1995.

[17] S. T. Zwisler, T. P. Enggaard, L. Noehr-Jensen et al., "The hypoalgesic effect of oxycodone in human experimental pain models in relation to the CYP2D6 oxidation polymorphism," Basic and Clinical Pharmacology and Toxicology, vol. 104, no. 4, pp. 335-344, 2009. 


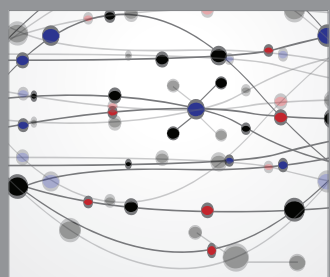

The Scientific World Journal
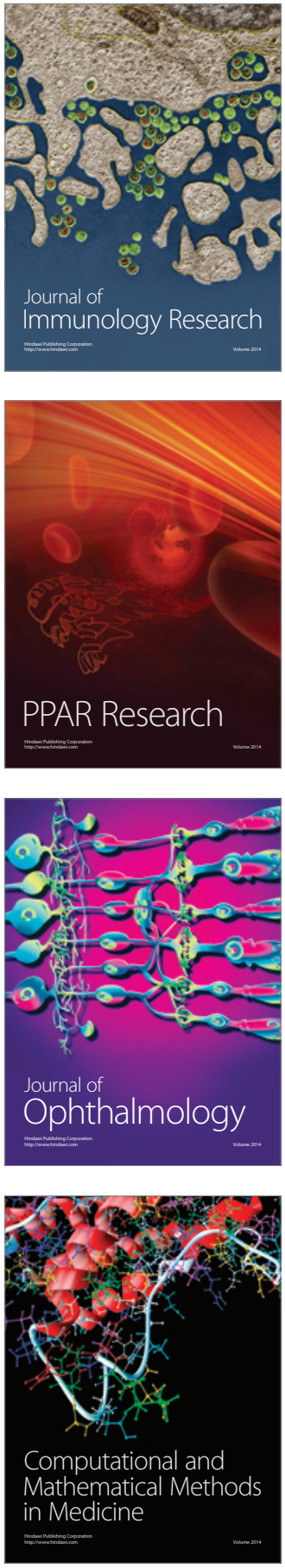

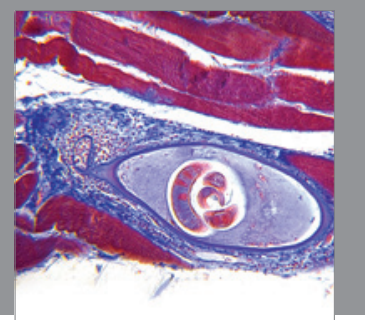

Gastroenterology

Research and Practice
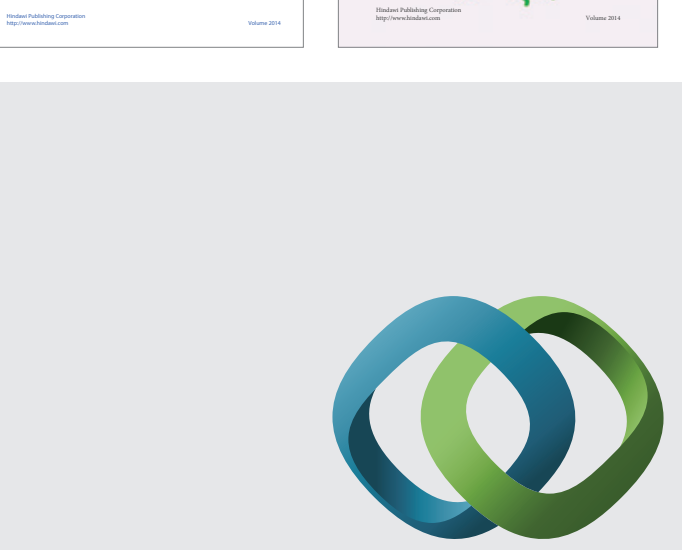

\section{Hindawi}

Submit your manuscripts at

http://www.hindawi.com
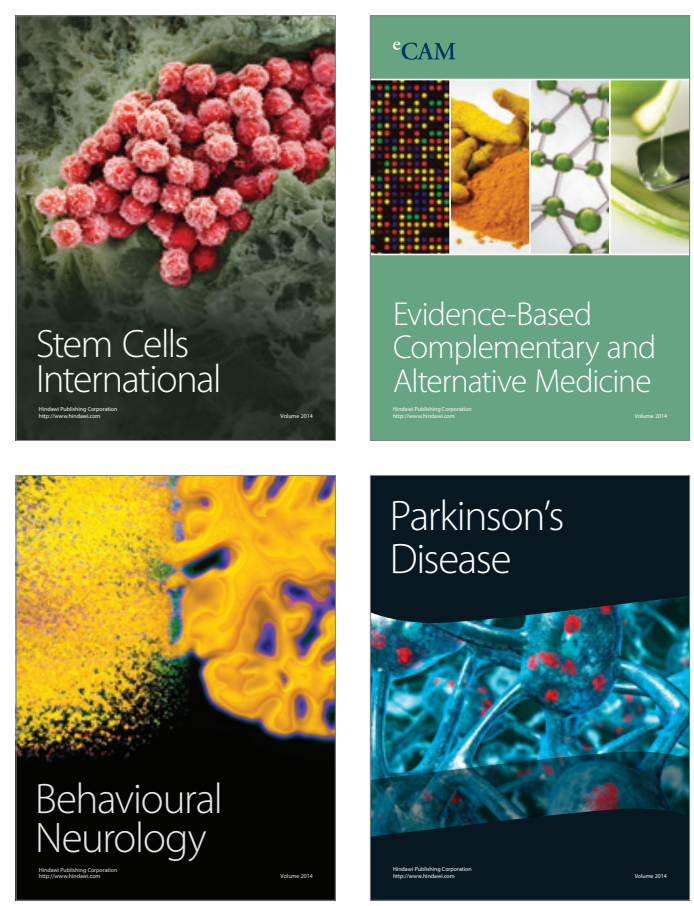

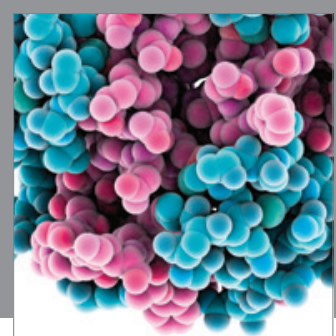

Journal of
Diabetes Research

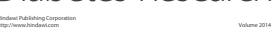

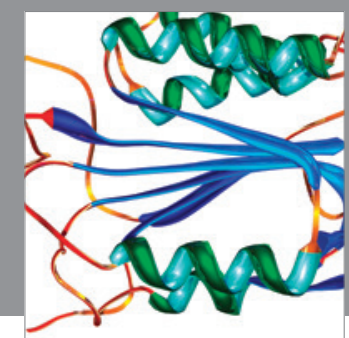

Disease Markers
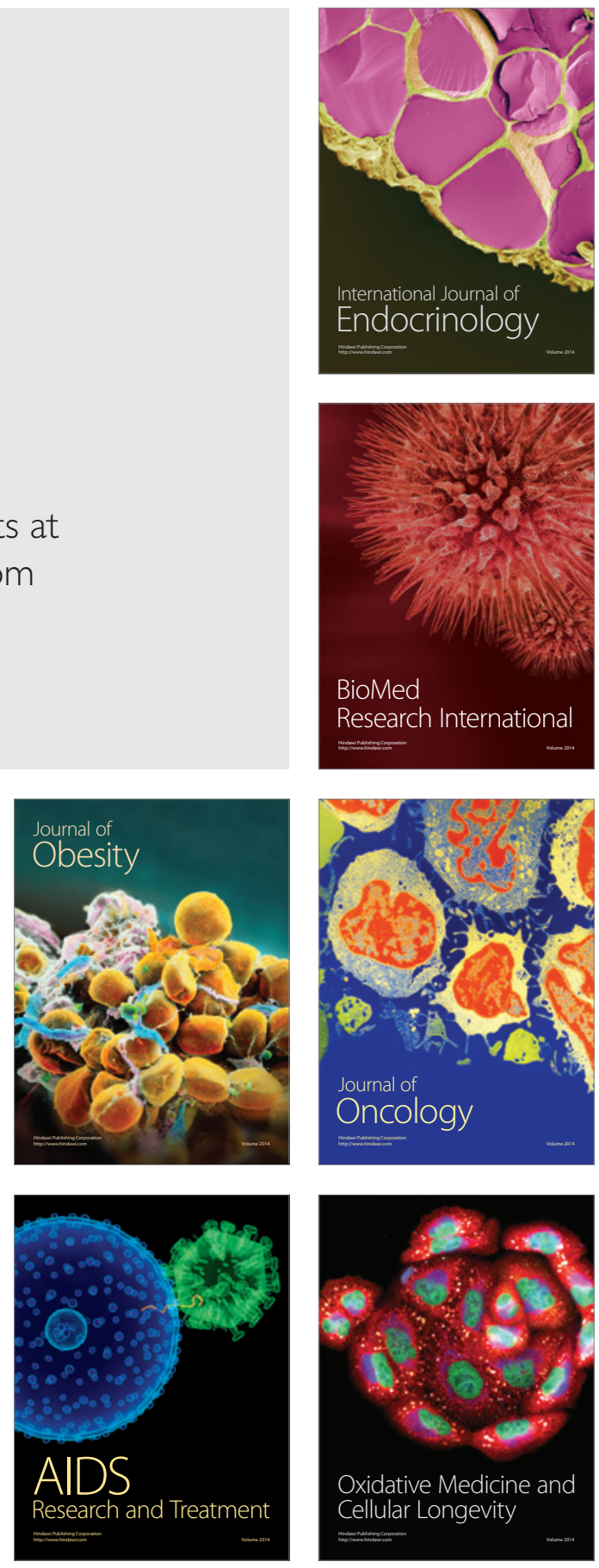